\title{
Badano, María del Rosario (comp). (2019). Educación superior y derechos humanos: reflexiones, apuestas y desafíos. Paraná: Editorial UADER, $416 \mathrm{pp}$.
}

\author{
Lucía Abbattista \\ mlabbattista@gmail.com \\ Facultad de Humanidades y Ciencias de la Educación, \\ Universidad Nacional de La Plata / Departamento de \\ Ciencias Sociales, Universidad Nacional de Quilmes, \\ Argentina
}

\author{
Cita sugerida: Abbattista, L. (2020). [Revisión del libro \\ Educación superior y derechos humanos: reflexiones, apuestas \\ $y$ desafios por M. Del R. Badano (comp.)]. Aletheia, \\ 11(21), e077. https://doi.org/10.24215/18533701e077
}




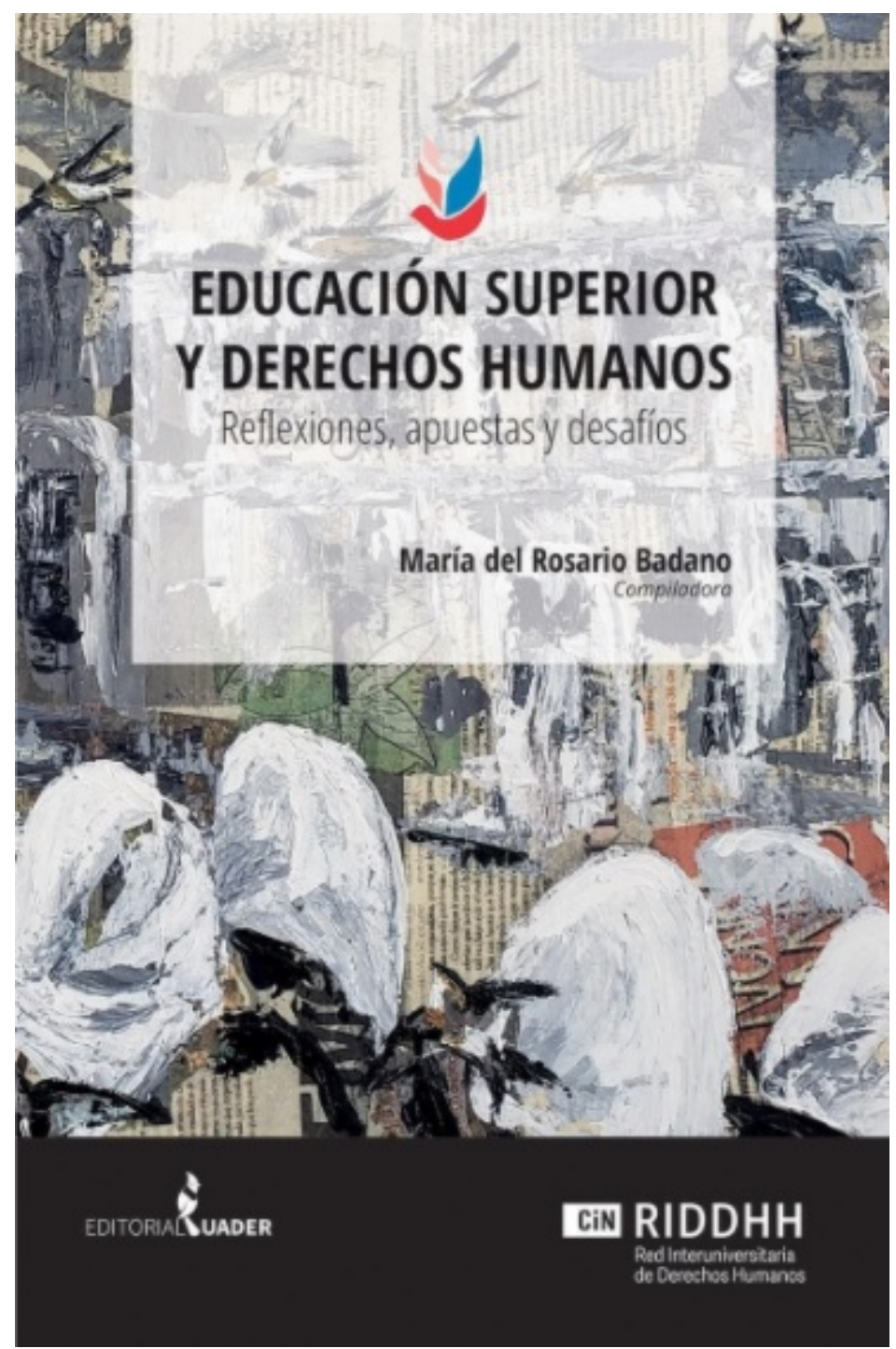

¿Cómo se teje una Red Interuniversitaria? ¿Cuánto tiempo se precisa? ¿Qué impulsos hacen falta? Esta compilación, realizada a partir del Primer Encuentro Nacional Educación Superior y Derechos Humanos que organizó la Red Interuniversitaria de Derechos Humanos de la Argentina (RIDDHH), ofrece numerosos indicios para contestar esas preguntas.

Los trabajos fueron reunidos por la magíster María del Rosario Badano, coordinadora ejecutiva de la Red desde su constitución formal en agosto de 2018, a partir de algunas presentaciones compartidas en el Encuentro. Con extensa trayectoria política dentro y fuera del ámbito académico ${ }^{1}$, Badano ha sido y sigue siendo una articuladora clave para la confluencia de diversas experiencias desarrolladas a lo largo y ancho del país.

Quienes recorran las páginas del libro podrán observar que aquel Primer Encuentro -realizado en Paraná entre el 14 al 18 de septiembre de 2018-, no se presenta como un punto de llegada, pero sí como coronación de un largo recorrido previo. También podrán encontrar, conforme avancen, la impronta de docentes e investigadores/as que, como veremos, llevan décadas tejiendo vínculos e institucionalidad para las prácticas y perspectivas vinculadas a los Derechos Humanos entre espacios de educación superior -universidades nacionales, provinciales e institutos de formación docente- y muy variados territorios. 
De todas maneras, más allá de su estrecha relación con el Encuentro, es importante aclarar que esta obra no se trata de una publicación de Actas de Congreso. De hecho, la mayoría de las ponencias presentadas fueron reunidas a posteriori en otro libro compilado por Rosana Ramírez y María Virginia Pissarello en formato digital $^{2}$. En el caso que aquí reseñamos, la RIDDHH y la Editorial de la Universidad Autónoma de Entre Ríos (UADER) propusieron otro tipo de intervención, más urgente, con la selección de algunos temas y voces puntuales para dar la batalla en un contexto caracterizado por la restauración neoliberal y el avance autoritario en América Latina.

Formalmente comienza con una presentación institucional acerca de la RIDDHH y otra acerca de la obra, luego incluye los discursos de bienvenida y apertura del Encuentro, 24 de las intervenciones realizadas en sus conversatorios y mesas, y culmina con la Declaración final firmada el 14 de septiembre de 2018.

En las presentaciones, bienvenidas y aperturas, las palabras presentes son las de Sandra Torlucci, rectora de la Universidad Nacional de las Artes y primera Rectora Coordinadora de la Red, Aníbal Sattler, rector de la UADER (que en 2019 sería electo rector Coordinador) y María del Rosario Badano. Luego, las 24 intervenciones están organizadas en cuatro secciones que entrelazan prácticas, inquietudes y sugieren caminos para recorrer -sin pretender constituirse en recetas-.

La primera sección recupera procesos de institucionalización de proyectos de diversa escala (cátedras libres, programas de extensión, áreas de $\mathrm{DDHH}$ ) y problematiza la articulación entre preocupaciones académicas, contextos políticos y demandas sociales; la segunda, si bien continúa en esa línea, se sumerge en particular en los desafíos y ensayos vinculados con la transmisión de la memoria a las nuevas generaciones y también expande su mirada hacia otros ámbitos de la educación como los programas e institutos de formación docente; la tercera sección repasa algunas agendas de investigación y producción de conocimiento renovadoras para el conjunto, con foco en diversos actores y conceptualizaciones; y la cuarta atiende a respuestas que se han dado frente a la vulneración de derechos en el territorio. Un dato al margen: Boaventura de Souza Santos es el referente más citado, seguido de cerca por Elizabeth Jelin.

Aun partiendo de diversas generaciones y formaciones -entre las que predominan especialistas en ciencias de la educación, sociólogos/as e historiadores/as-, los/as autores/as comparten algunas inquietudes que nos hablan, también, de la época en que se inscriben. Entre estas hay cinco que me gustaría destacar: 1) la preocupación por la memoria, tanto en lo que hace a su transmisión como a la supervivencia de su potencial crítico y transformador; 2) la inquietud por las herencias coloniales/colonialistas en nuestra cultura en general y en la educación superior en particular; 3) la inquietud por el avance de la mercantilización en nuestras instituciones y relaciones (en el marco de otras graves regresiones en la región), 4) la necesidad de atender desde nuestros espacios a la vulneración de derechos que engendran las múltiples violencias del capitalismo, el patriarcado y el capacitismo y 5) la preocupación por los aportes específicos que están al alcance de las instituciones de educación superior para la construcción con otros sujetos de un horizonte emancipatorio y más justo.

Por otra parte, para los autores que provienen de las universidades públicas, el hecho de que se cumplieran 100 años de la Reforma Universitaria, brindaba un marco propicio para la introspección. Con el ejercicio de una memoria institucional crítica, estos artículos permiten vislumbrar pequeñas y grandes iniciativas que fueron dando forma a una nueva tradición cultural y política en la que la Red hace pie. Podemos mencionar, en ese sentido, trabajos como el de Graciela Daleo sobre las extensión de territorios de la UBA a partir de la Cátedra Libre de DDHH de Filosofía y Letras, fundada en 1994; el de Juan Pablo Abratte (UNC, fallecido poco después de la publicación) sobre las implicancias de entender a la educación superior como bien público y social, así como un derecho humano fundamental y responsabilidad de los Estados; el trabajo de Verónica Cruz, prosecretaria de DDHH de la UNLP sobre la construcción de un espacio de gestión dispuesto a forjar una cultura de derechos humanos en el ámbito universitario; la historización de las mencionadas Badano, Ramírez y Pissarello sobre el desarrollo de la Cátedra de DDHH curricular para todas las carreras en la UADER; el de Matías Penhos (UNQ) sobre las intervenciones institucionales en materia de derechos de las 
personas en situación de discapacidad y derecho a la comunicación; y el de Camila Pérez (UNSAM) sobre la experiencia del Grupo de Estudios Sobre Educación en Cárceles. No son los únicos, pero su mención permite dar cuenta de la variedad de iniciativas y actores que fueron urdiendo una Red como esta durante décadas.

La Declaración final, a su vez, asume el carácter de un manifiesto y retoma varios de los temas tratados. Adhiere a los principios declarados en la Conferencia Regional de Educación Superior (CRES) del 2018, por lo cual llama a las universidades públicas a mediar estrategias capaces de lograr el ingreso y permanencia de los y las estudiantes, en el marco del respeto a la libertad de pensamiento y la pluralidad cultural (artículo 1). También resalta la necesidad de abandonar lógicas endogámicas para contribuir a los procesos de transformación social, incorporando enfoques extracéntricos, decoloniales, de género, con sentido humanista y ambiental. Para este Documento, las mujeres, las organizaciones sociales, las comunidades originarias y afrodescendientes, las niñeces, las personas migrantes, los colectivos LGBTTTIQ, los y las adultos mayores, las personas privadas de su libertad y todos aquellos sectores socialmente excluidos tienen que cumplir un rol preponderante y significativo en una universidad crítica y comprometida (artículo 2). Se destacan, a continuación, los compromisos ineludibles con la Democracia y la plena vigencia del Estado de Derecho, como garantía de respeto a los derechos humanos, sociales, políticos, económicos y culturales del pueblo, contra el ajuste y la violencia institucional (artículo 3) y se apela a la construcción de la Memoria como un principio educativo y académico fundamental frente al negacionismo y los retrocesos en la búsqueda de verdad y justicia (artículo 4).

Por todo lo antedicho, para quienes quieran impulsar propuestas de docencia, investigación, extensión y gestión en diversos puntos del país, y especialmente para quienes no pudieron concurrir a aquel Primer Encuentro en Paraná, el libro cumple también con el objetivo de presentar la Red como marco de trabajo y convocar a volcar los múltiples esfuerzos en una dirección común.

\section{Notas}

1 Para conocer más sobre María del Rosario Badano recomiendo su testimonio disponible en la Biblioteca Nacional Mariano Moreno, 8 de mayo de 2015. https://www.bn.gov.ar/micrositios/multimedia/ddhh/testimonio-de-maria-de 1-rosario-badano

2 Ramírez, Rosana y Pissarello, María Virginia (comp.) (2019).Educación Superiory Derechos Humanos. Políticas, prácticas y dispositivos a 100 años de la Reforma Universitaria. Paraná: Ed. UADER, 850 páginas. http://riddhh.cin.edu.ar/notic ias/14-ponencias-del-primer-encuentro-nacional-derechos-humanos-y-educacion-superior 